\title{
De la pasividad a la justa temporalidad del desastre en Maurice Blanchot
}

\section{From the passivity to the just temporality of the disaster in Maurice Blanchot}

\author{
IDOIA QUinTANA DOMÍNGUEZ \\ Université Catholique de Louvain \\ idoiaqui@yahoo.es
}

Recibido: 28-10-2014

Aceptado: 06-02-2015

\section{Resumen}

A partir de los años 70, y especialmente en La escritura del desastre, el término "pasividad" adquiere una relevancia notable en el pensamiento de Maurice Blanchot. Siguiendo el rastro de esta noción que señala hacia una ruptura de la determinación tradicional del sujeto, veremos en un primer momento de qué modo se matiza y cómo se acota respecto a ciertas nociones, algunas de ellas utilizadas previamente: la noción de rechazo central en su reflexión política, el inconsciente y una temporalidad que, aún dando cabida a ciertas alteraciones, sigue siendo fácilmente reversible en la continuidad de lo vivido. En un segundo momento, examinaremos la vinculación entre la pasividad y la noción de desastre, lo que nos conducirá a un análisis de una temporalidad que pondrá en cuestión la figura del advenimiento a la vez que implicará una reflexión sobre la responsabilidad y la justicia. De este modo, pretendemos mostrar la relevancia de esta noción como una de las piezas clave para comprender el desarrollo filosófico de este autor.

Palabras clave: Pasividad, desastre, temporalidad, responsabilidad, justicia.
Abstract
Starting from the 70s and especially in The Writing of the disaster, the term "passive" gains a considerable importance in the thought of Maurice Blanchot. Following the trail of this notion that points to a breakdown of the traditional deter- 
mination of the subject, we shall see at first how it is clarified and delimited with respect to other notions previously employed: the notion of rejection, core in his political thought, as well as to the unconscious and to a temporality that even giving space for certain alterations remains easily reversible in the continuity of the experienced. In a second stage, we examine the link between passivity and the notion of disaster, which will lead us to an analysis of a certain temporality that will call into question the figure of the advent while at the same time will imply a reflection on the responsibility and the justice. In this way, we intend to show the relevance of this notion as one of the key elements to understand the philosophical development of this author.

Keywords: Passivity, disaster, temporality, responsibility, justice.

Lo pasivo no tiene por qué tener lugar, pero, implicado en lo que vuelve que separándose de la vuelta se hace por ella desvío, es el tormento del tiempo que ya habiendo siempre pasado viene como vuelta sin presente, viniendo sin advenir en la paciencia de la época, época inenarrable, destinada a la intermitencia de un lenguaje descargado de habla, desapropiado, y que es la interrupción [arrêt] silenciosa de lo que, sin obligación, sin embargo hay que responder. Responsabilidad de una escritura que marca desmarcándose, es decir, quizá -a fin de cuentas- borrándose (tan pronto como a la larga -hace falta todo el tiempo para eso-), en la medida en que parece dejar huellas eternas u ociosas.

Maurice Blanchot, La escritura del desastre

\section{Rasgos de la pasividad blanchotiana}

La noción de pasividad adquiere en la obra de Blanchot un carácter desligado de su uso corriente, alejándose de las diversas acepciones de este término como serían la de sometimiento - que abarcaría incluso el quietismo místico- la de inercia o la de estado de padecimiento. Dentro de la terminología propia de Blanchot, hasta aproximadamente los años setenta, la pasividad se relaciona con las nociones de sufrimiento o desdicha.

El sufrimiento y la desdicha ponen de manifiesto lo que excede el poder de padecer una dolencia. Muestran la imposibilidad para el sujeto de aprehender una experiencia de la que no es capaz de hacerse cargo, que excede la capacidad de padecerla en primera persona así como de situarla en un tiempo presente: "Hay 
sufrimiento, habría sufrimiento, no hay «yo» sufriente, y el sufrimiento no es llevado (todavía menos vivido) a un presente[...] El tiempo sin presente, el mí sin mí [le moi sans moi], nada de lo que se pueda decir que la experiencia - una forma de conocimiento -revelaría o disimularía"1. La experiencia que desborda la experiencia del sufrimiento no remite a un sujeto, ni siquiera a un sujeto paciente, sino a una relación con lo otro que interrumpe la vuelta sobre un sí mismo. En este sentido Blanchot afirma: "Pero la desdicha no autoriza el mí, el yo desdichado, lo cual conduce a pensar -sólo a pensar- que la desdicha siempre ha deshecho el mí, sustituyéndolo por la relación otra y con el otro y que, sin embargo, lo encierra en una singularidad puntual en donde no tiene derecho a ser mí, ni siquiera un mí singular, ni siquiera un mí que sufre"'2.

El sufrimiento pone de relieve un aspecto fundamental de la pasividad. Si en él el sujeto activo desaparece, también desaparece el sujeto pasivo, aquel que padece el sufrimiento. Así se presenta un cuestionamiento radical del sujeto en su determinación tradicional, puesto que se está eliminando al receptor individual de la experiencia. No obstante, el viraje por el que Blanchot muestra el desajuste de la experiencia a partir del sufrimiento puede resultar equívoco. En el uso habitual del término sufrimiento hay una exaltación de la parte pasiva del sujeto como aquel que padece un dolor o una pena. Por esta razón, Blanchot, después de afirmar un paralelismo entre la pasividad y el sufrimiento: "La pasividad: no podemos evocarla más que por un lenguaje que se trastoca. En otro tiempo, recurría al sufrimiento"3, debe admitir que este último es demasiado confuso: "Pero la palabra sufrimiento es demasiado equívoca"4.

La pasividad no se deja tematizar y la alusión al sufrimiento y la desdicha no dejan de ser figuras confusas que señalan hacia una experiencia y, a partir de ella, a su conocimiento. El término de pasividad es reivindicado por Blanchot, pero al mismo tiempo admite que al darle un nombre por el que pueda ser conocida, tematizándola o conceptualizándola, la pasividad se vuelve dependiente de la relación dual activo/pasivo. Las razones de esta necesaria traición son enumeradas: el discurso se desarrolla en vistas a una coherencia; el discurso es sintético, y esto quiere decir que en él domina la fuerza que reúne y unifica. En la medida en que se trata de representarla y hacerla presente, este mismo gesto aleja de lo que la pasividad pone en juego: "Nos es muy difícil -y por ello más importante- hablar de la pasividad, pues no pertenece al mundo y no conocemos nada que sea completamente

\footnotetext{
1 Blanchot, M., La escritura del desastre, trad. de Pierre de Place, Caracas, Monte Ávila, 1987 , p. 20. Modificaremos ligeramente la traducción de este libro.

2 Blanchot, M., El paso (no) más allá, trad. de Cristina de Peretti, Barcelona, Paidós, 1994, p. 153.

3 Blanchot 1980, op. cit. (nota 1), p. 20.

4 Ibidem.
} 
pasivo (al conocerlo, lo transformaríamos inevitablemente). La pasividad opuesta a la actividad, tal es el campo siempre restringido de nuestras reflexiones" 5 . Es más, la razón de ello es que estos rasgos por los que se intenta pensarla proceden de esa parte -el entendimiento, la consciencia, la voluntad, etc.- que guarda relación con el poder de presentar o representar. Por esa razón, Blanchot advierte que la pasividad no tiene que ver con estas capacidades, sino con la parte "inhumana" del hombre, la parte destituida, separada, no operativa y en ningún caso representativa. Por lo tanto, la pasividad interrumpe tanto su propia tematización como su experiencia. En este sentido, Blanchot afirma que "la pasividad, escapando a nuestro poder de dar prueba de ella (de probarla), se propone o se depone como lo que interrumpiría nuestra razón, nuestra habla, nuestra experiencia" 6 . No se trata, como afirma Marlène Zarader, de una indistinción entre el sujeto y el objeto, sino de una desaparición o una retirada del sujeto, "una experiencia sin sujeto ni conciencia, una experiencia «pura», «radical», «absoluta», que no soporta más el nombre de experiencia $[\ldots]$ pero que no deja por ello de imponerlo"7.

La pasividad, si se quiere pensar fuera de la remisión a lo pasivo como polo opuesto a lo activo, no sería lo que en el pensamiento hay de pasivo, sino lo que Blanchot denominará como "un pasivo de pensamiento"8. La difícil tarea de abordar lo pasivo atendiendo al lugar que Blanchot le concede -no como lo que acompaña al sujeto exponiéndolo a la mayor de las violencias, sino como el verdadero sujeto que desplaza al sujeto de la experiencia-implicará acotar este término, y para ello Blanchot iniciará una suerte de revisión con el fin de separar lo pasivo de aquello que, presentándose como tal, en realidad no es más que la parte de negatividad inapropiable de una cierta experiencia límite, de aquello que excede al poder del sujeto, pero que aún no señala hacia una pasividad sin medida:

El sufrir (subir), el subissement -para formar esta palabra que no es sino el doblete de súbitamente, la misma palabra chafada-, la inmovilidad inerte de ciertos estados llamados de psicosis, el padecer de la pasión, la obediencia servil, la receptividad nocturna que supone la espera mística, el despojamiento entonces, la desgarradura de sí a sí mismo, el desprendimiento por el cual uno se desprende incluso del desprendimiento, o bien la caída (sin iniciativa ni consentimiento) fuera de sí -todas estas situaciones, incluso si algunas están al límite de lo cognoscible y designan una cara escondida de la

\section{Ibidem.}

6 Ibidem, p. 21.

7 Zarader, M., L'être et le neutre. À partir de Maurice Blanchot, Verdier, 2001, p. 248. En este mismo libro, la autora analiza la relación entre la noción de pasividad blanchotiana, la fenomenología y la reflexión en torno a la pasividad realizada por Lévinas (cfr. pp. 130-136; 248-261).

8 Ibidem, p. 35. 
humanidad, no nos hablan casi nada de lo que buscamos entender al dejar que se pronuncie esta palabra desconsiderada: pasividad. ${ }^{9}$

Es importante indicar cómo Blanchot separa aquí lo que hasta ese momento había sido determinante para dar cuenta de lo que pone al sujeto fuera de sí, así como de lo que se podría llegar a entender como un alejamiento de la "experiencia interior" de Bataille ${ }^{10}$. Estas experiencias límite -bien porque alguno de estos estados permiten de alguna manera una reasunción posterior, bien porque permiten algún tipo de desvelamiento o de conocimiento aunque este sea el propio de la teología negativa, o bien porque hablan de lo episódico o eventual-, Blanchot no transige en contenerlas dentro de "la pasividad más pasiva" 11.

Igualmente, aquel tipo de habla extraña al poder político que Blanchot recoge bajo la noción de rechazo no tiene por qué responder a esta pasividad radical. Si bien el rechazo es definido como "el primer grado de la pasividad" 12 , puede referirse a la sola toma de posición deliberada de un "yo que rechaza"13. Esta actitud responde a una de las exigencias que hay que atender y que no implica que deba hacerse fuera de todo consentimiento (aquí se puede encontrar la postura que toma el intelectual y la relación con la firma como el acto esencial del compromiso). También es preciso, y Blanchot subraya este aspecto como un deber, "responder por el rechazo, la resistencia y el combate, volviendo al saber (volviendo, si es posible -pues puede que no haya retorno-), a un yo que sabe, y que sabe que está expuesto, no a Autrui, sino al "Yo" adverso, al Todo-Poderoso egoísta, la Voluntad mortífera" 14 . Pero al igual que existe un rechazo dialéctico, donde el que rechaza se convierte en cómplice de lo que es rechazado precisamente por entrar en ese juego dialéctico, hay otro rechazo que no atiende a la misma exigencia, que no habla el mismo lenguaje. Blanchot insiste a lo largo de toda su obra sobre esta doble exigen-

\footnotetext{
9 Ibidem, pp. 20-21. desastre.

12 Blanchot 1980, op. cit. (nota 1), p. 22.

13 Ibidem.

14 Ibidem, p. 24.
}

10 "Sentimos que no podría haber experiencia del desastre incluso entendiéndola como experiencia-límite (la experiencia-límite es como Blanchot denomina la «experiencia interior» de Bataille como podemos leerlo en el artículo recopilado en La conversación infinita que lleva este mismo título). Este es uno de sus rasgos: destituye toda experiencia, le retira la autoridad, vela solamente cuando la noche vela y no vigila”. Ibidem, p. 49.

11 Ibidem, p. 37. La pasividad más pasiva remite a "la pasividad más pasiva que toda pasividad" de la que habla Lévinas especialmente en Humanismo del otro hombre, trad. de Daniel Enrique Guillot, Buenos Aires, Siglo XXI, 1974, p. 123 y 125, y que Blanchot aborda, no sin dar cuenta de un distanciamiento en puntos fundamentales, en La escritura del 
cia, sobre un doble lenguaje, o al menos sobre la necesidad del "más de uno" a través de una compleja lógica que implica un "a la vez" necesario. En esta línea, afirma, "por eso hace falta al menos dos lenguajes o dos exigencias, una dialéctica, otra no dialéctica [...] haría falta ser el sujeto libre y hablante y, a la vez, desaparecer como el paciente pasivo que atraviesa el morir y no se muestra" 15.

\section{Relación entre la noción de pasividad y otros motivos de la obra de Blanchot}

La noción de pasividad recorre los motivos principales de la obra de Blanchot 16 . El morir, retirando la muerte como acontecimiento, pertenece a un pasado remoto, nunca vivido, nunca experimentado ni trazado que corresponde a esta pasividad que rompe con la noción de experiencia como vivencia y del amplio campo que de esta se deriva: presencia, presente, propiedad, consciencia, etc. De ahí la extraña afirmación: "Morir quiere decir: muerto, tú lo estás ya, en un pasado inmemorial, de una muerte que no fue la tuya, que no has vivido ni conocido"17. Inmemorial, fuera de toda experiencia, es decir, aquello que transcurre sin tener lugar, eso es a lo que Blanchot llama "la pasividad del morir"18. Una pasividad que ha dejado de lado la impaciencia por lo que ha de tener lugar, que ha olvidado un futuro donde el fin sería posible.

Blanchot realizará una breve incursión en el campo del psicoanálisis para cuestionar lo que define como, quizá, "terapéuticamente útil" pero, así todo, ajeno a la pasividad. La pasividad no es el inconsciente ya que, entre otras cosas, este afirma una etapa necesaria en el proceso de formación del sujeto. La pasividad, el campo yermo del olvido, lo que nunca podría dar lugar a un ser individual puesto que en ella nada se individualiza, acoge "esa muerte incierta, siempre anterior, atestación de un pasado sin presente"19. Puesto que "el olvido es la exigencia pasiva"20 -exigencia en el sentido de que ella llama al movimiento "del pasado hacia lo intraspa-

\footnotetext{
15 Ibidem, p. 25.

16 No entraremos en el lugar que ocupa la pasividad en la experiencia literaria o de lo imaginario. Para estos aspectos, remitimos a la obra de Thomas Carl Wall Radical passivity. Lévinas, Blanchot, and Agamben, Nueva York, State University of New York, 1999, donde el autor defiende la tesis de que la "pasividad radical produce lo imaginario, produce algo así como la ficción" (p. 2).

17 Ibidem,p. 61.

18 Ibidem,p. 25.

19 Ibidem,p. 61.

20 Remitimos a la cita del original francés ( L'Écriture du désastre, París, Gallilée, 1980, p. 134) debido a la omisión del fragmento citado en la traducción española.
} 
sable" $21_{-}$no se puede pretender que ciertos "acontecimientos" -en concreto Blanchot se refiere a las "agonías primitivas" de la infancia donde aún no existe un sujeto como tal- sean devueltos a un presente en el que fijarse, teniendo lugar en una actualidad diferida, "en el presente de un recuerdo (es decir, de una experiencia actual) la pasividad de lo desconocido inmemorial" 22 . Por un lado, esta operación restituye lo no-vivido, individualizándolo, en un saber. Pero, además, lo devuelve a un tiempo lineal aunque sea llevado a él por medio de la alteración ${ }^{23}$. Esta misma alteración es la que se ha querido señalar citando la célebre frase de Hamlet: "The time is out of joint" con el fin de señalar un tiempo que no se corresponde con los principios de linealidad y homogeneidad, cuyo eje es el presente. A través de ella se trata de mostrar la inestabilidad de ese tiempo, un tiempo que dilatándose o contrayéndose, alterándose por juegos de reminiscencias o actualizaciones, muestra un desplazamiento sin fin. Pero si de nuevo esta expresión excluye un tiempo ordenado en torno a lo presente y desarrollado como sistema, como también lo proponía el psicoanálisis, aún Blanchot radicalizará esta noción temporal desplazándola hacia el desastre como contratiempo. Así podemos leerlo en un fragmento de La escritura del desastre que retoma la imagen shakesperiana.

El presente, si se exalta en instantes (apareciendo, desapareciendo), olvida que no podría ser contemporáneo de sí mismo. Esta no-contemporaneidad es un pasaje siempre traspasado, lo pasivo que, fuera de tiempo, lo desarregla como forma pura y vacía donde todo se ordenaría, se distribuiría de forma igualitaria o desigual. El Tiempo desarreglado, fuera de sus goznes, se deja todavía atraer, aunque sea a través de la experiencia de la fractura, en una coherencia que se unifica y se universaliza. Pero la experiencia inexperimentada del desastre, retirada de lo cósmico que es demasiado fácil de desenmascarar como ruina (la falta de fundamento donde se inmovilizaría de una vez por todas, sin problemas ni cuestiones, todo lo que nos es dado pensar), nos obliga a desprendernos del tiempo como irreversible, sin que el Retorno asegure la reversibilidad. 24

Respetar la exigencia de la pasividad implica habitar el abismo que arruina todo fin, implica un fuera de tiempo como ausencia de tiempo, no sólo otro tiempo sino lo otro del tiempo. A este abismo Blanchot le dará el nombre de desastre, un desastre que atraviesa la escritura, una escritura que es escritura por la pasividad. Toda

\section{Ibidem,p. 21.}

22 Ibidem,p. 61.

23 Esta incursión en el campo del psicoanálisis guarda relación con «¿Una escena primitiva?», un breve relato posiblemente autobiográfico inserto en La escritura del desastre. Entre los escritos que han abordado este relato, cabe destacar el de Philippe Lacoue-Labarthe en Agonie terminée, agonie interminable. Sur Maurice Blanchot, París, Galilée, 2011.

24 Ibidem, pp. 70-71. 
escritura es escritura del desastre siempre que sea "sin importancia" 25 y siempre que se acepte que "no escribir sin poder [...] supone el paso por la escritura" 26 . La posible relación que se entabla entre la escritura y la pasividad pasa por el desastre. Ambas implican la borradura o la extenuación del sujeto y un cambio de tiempo, "suponen que entre el ser y el no ser, algo que no se cumple llegue sin embargo como habiendo sido ya desde siempre sobrevenido"27. Esta referencia a un tiempo otro se explicará como la amenaza del desastre cuya condición, la condición de su venida, es que no llegue nunca y que, sin embargo, no deje de llegar, afectado así por una iterabilidad que atraviesa el acontecimiento retirándole la puntualidad de un presente. Fuera de todo horizonte de espera, el desastre se presenta como amenazante, sin amenazar no obstante al "yo" sino a la parte pasiva, retirando la posibilidad de hacerle frente como también la posibilidad de ser alcanzado por él. No se instala en un futuro, pero es inminente, siempre pasado sin haber llegado, en una tensión hacia lo que viene pero deteniendo su llegada.

La problemática temporal que propone Blanchot se agudiza con la figura del desastre: el desastre es lo que impide el fin, el encuentro como fusión, la historia como el relato de una teleología. El desastre es el que "detiene toda venida" 28. "Cuando el desastre sobreviene, no viene [...] el futuro, tal como lo concebimos en el orden del tiempo vivido, pertenece al desastre"29; su tiempo es el de la inminencia sin presencia, el de la inminencia sin advenimiento. En este sentido, Roger Laporte indica en uno de sus libros sobre Blanchot:

Al Ereignis, pensado por Heidegger, se opone exactamente el Desastre tal y como Blanchot más que pensarlo lo designa. El Ereignis es a la vez advenimiento y apropiación, aquello sin lo cual el Ser no vendría a la presencia, mientras que "el desastre está del lado del olvido, el olvido sin memoria, la retirada inmóvil de aquello que no ha sido trazado. 30

Nada entonces más alejado a esta "designación" del desastre que el pensamiento del advenimiento y de la apropiación. Nada más alejado que el pensamiento profético que anuncia la llegada del acontecimiento como porvenir programado, del fin adelantado como siempre se ha pensado la muerte cuando es definida como lo más propio del ser. Pero si el desastre rechaza este acontecimiento capaz de poner fin,

25 Ibidem, p. 18.

26 Ibidem.

27 Ibidem, p. 20.

28 Ibidem, p. 9.

29 Ibidem.

30 Laporte, R., Maurice Blanchot. L'ancien, l'effroyablement ancien, Montpellier, Fata Morgana, 1987, p. 39. 
descubre en su lugar la pasividad y una extrema paciencia que abre a la espera infinita, sin horizonte: "El desastre, ruptura con el astro, ruptura con toda forma de totalidad, sin, entre tanto, rehusar la necesidad dialéctica de un cumplimiento, profecía que no anuncia más que el rechazo de lo profético como simple acontecimiento por venir, abriendo, sin embargo, descubriendo la paciencia del habla vigilante" 31 .

\section{De la exigencia de la pasividad a la temporalidad del desastre: advenimiento, justicia, responsabilidad}

El tiempo mesiánico será el paradigma que, según Blanchot, pondría en entredicho esta forma de ligar el tiempo a la presencia, de ligar la presencia al presente como momento culminante. Esta es la misma reflexión que asedia la cuestión de la muerte, es decir, la imposibilidad del advenimiento del acontecimiento último. Pero si el tiempo mesiánico es el que Blanchot exalta como paradigma de la separación entre acontecimiento y advenimiento, se trata de una interpretación del mesianismo no teológica que podría corresponder a lo que Derrida invita a pensar a partir de la expresión, de tintes blanchotianos, "un mesiánico sin mesianismo" 32 . Desde esta interpretación concreta del mesianismo -que habría que ver en qué medida Blanchot la une o la hace depender de la singularidad judía, el "pueblo sin mitos" como ha repetido en varias ocasiones ${ }^{33}$-, la espera ya no se relaciona ni con un futuro predecible ni con un pasado accesible, sino precisamente con cierta "experiencia de lo imposible", lo que abre a una espera que, al esperar desde más allá de lo esperado, se convierte en "espera de la espera" 34 . Esto, a su vez, corresponde a la con-

31 Blanchot 1980, op. cit. (nota 1), pp. 68-69.

32 Derrida, J., Espectros de Marx, trad. de José Miguel Alarcón y Cristina de Peretti, Ed. Trotta, 1995, p. 73. Esta cita es de gran importancia por lo que evocaremos el párrafo en el que se inscribe: "Pues bien, lo que sigue siendo tan irreductible a toda deconstrucción, lo que permanece tan indeconstructible como la posibilidad misma de la deconstrucción, puede ser cierta experiencia de la promesa emancipatoria; puede ser, incluso, la formalidad de un mesianismo estructural, un mesianismo sin religión, incluso un mesiánico sin mesianismo, una idea de la justicia -que distinguimos siempre del derecho e incluso de los derechos humanos-y una idea de la democracia -que distinguimos de su concepto actual y de sus predicados tal y como hoy en día están determinados-". Habría que añadir que "indeconstructible" señala hacia un exceso que hace de su deconstrucción algo interminable. Por lo tanto, no se trata de mantener un reducto a salvo de la deconstrucción, sino de mostrar la tarea infinita de la deconstrucción.

33 Cf. Los intelectuales en cuestión, trad. de Manuel Arranz, Madrid, Tecnos, 2003, p. 103, y en la carta que se encuentra en Nancy, J.-L., Maurice Blanchot. Passion politique, París, Galilée, 2011, p. 51

34 Blanchot 1980, op. cit. (nota 1), p. 101. 
dición de toda llegada: que el advenimiento no tenga lugar permite que este no deje de llegar -un "ven" eterno que no se acalla con la presencia, pues esta no es garantía suficiente para romper con la obligación de la espera-. Sólo porque esta presencia no es garantía del advenimiento final, porque expone a algo que desborda toda presencia y pone en relación con la pasividad -como enuncia el narrador en las últimas palabras de La sentencia de muerte: "le digo eternamente: «Ven», y eternamente, ella está ahí" $35-$, la espera pierde todo fin y finalidad.

En este sentido, se podría continuar esta reflexión sobre el desastre viendo la relación que guarda con el fin de los tiempos, con el apocalipsis. Mientras que el apocalipsis anuncia el fin, el desastre anuncia, por el contrario, el fin del fin, la imposibilidad de acabar o el sinfín del fin. En otros términos, "el apocalipsis sin apocalipsis" 36 . La visión apocalíptica del cristianismo, comprendida desde un punto de vista teleológico, es opuesta por Blanchot al mesianismo judío, para el cual "el advenimiento mesiánico no significa el fin de la historia, la supresión de un tiempo más futuro que el que cualquier profecía podría anunciar"37. El desastre que detiene toda venida, toda presencia, intercambia estas por lo infinito de una espera paciente que retira hasta el poder de ser paciente abriendo a la pasividad, abriendo a un tiempo fuera del tiempo, a una ausencia de tiempo, a la inminencia de un instante que no ilumina ni se fija.

Sería preciso determinar entonces las características del fin que se anuncia en el Apocalipsis: es el fin de la humanidad, el fin de los tiempos, pero también el Juicio final donde se cumple la Justicia divina. Trasladando la justicia al fin de los tiempos, el Veredicto final es el advenimiento tanto de la Justicia como de la Verdad, quizá de la verdad de la Justicia o de la justicia como Verdad, lo que a su vez sería posible traducir como la verdad de la Verdad ${ }^{38}$. Un tiempo que no esté ordenado por

35 Blanchot, M., La sentencia de muerte, trad. de Manuel Arranz, Valencia, Pre-textos, 2002, p. 79.

36 Cf. Derrida, J., Sobre un tono apocalíptico adoptado recientemente en filosofía, trad. de Ana María Palos, México D.F., Siglo XXI, 2006, p. 76: "Existe el apocalipsis sin apocalipsis. La palabra $\sin$ la pronuncio aquí dentro de la sintaxis tan necesaria de Blanchot quien a menudo dice $\mathrm{X} \sin \mathrm{X}$. El sin marca una catástrofe interna y externa del apocalipsis, un cambio de sentido que no se confunde con la catástrofe anunciada o descrita en los escritos apocalípticos sin por ello serles extraña. La catástrofe, aquí, sería tal vez la del apocalipsis mismo, su repliegue y su fin, una clausura sin fin, un fin $\sin$ fin. [...]¿Y si ese «fuera del apocalipsis» estuviera en el apocalipsis?".

37 Blanchot 1980, op. cit. (nota 1), p. 121.

38 Cf. Derrida 2006, op. cit. (nota 34), pp. 55-56: "La verdad misma es el fin, el destino, y que la verdad se descubra es el advenimiento del fin. La verdad es el fin y la instancia del juicio final. La estructura de la verdad sería aquí apocalíptica. Y por eso es que no puede haber verdad del apocalipsis que no sea verdad de la verdad". 
este fin deberá poner en cuestión este principio de Justicia universal (una justicia que se hace de una vez por todas) y de verdad que de él se deriva. Así lo hace Blanchot en las últimas páginas de La escritura del desastre donde podemos leer: "Y, ¿por qué la idea del Mesías?, ¿por qué la necesidad del acabamiento en la justicia? ¿Por qué no soportamos, no deseamos lo que es sin fin?"39. Blanchot nos muestra aquí la proximidad entre el acabamiento, el fin, la parusía, el advenimiento final caracterizado por la llegada del Mesías en cuanto presencia presente, y la justicia que reclama esta misma estructura -el hacer justicia, el dictar sentencia irrevocable-. La justicia sería según esta lógica equivalente al fin, como si sólo pudiera advenir como el fin último y como si hubiera que esperar a ese fin para que la justicia pudiera tener lugar, como si hubiese que esperar su advenimiento. El tiempo de la justicia que corresponde al tiempo apocalíptico se coordina con este tiempo teleológico, programado, que dice el fin último y su adecuación. La justicia concerniría así a la espera de este fin, y no a "la espera de la espera", al tiempo del desastre, a la exigencia de la pasividad.

Sin embargo, si Blanchot pone en cuestión la reciprocidad entre justicia y acabamiento, no por ello hunde la justicia en la indeterminación ya que, si por algo se caracterizan las referencias a la justicia en su obra, es por estar vinculada a una urgencia que la hace perentoria. Esto no implica que actúe movida por una impaciencia que busca lo concluyente, sino, al contrario, por la paciencia de la pasividad. De esta forma se puede comprender, siempre que no se oponga simplemente la pasividad a la actividad, la paciencia a la impaciencia, que "la paciencia es la urgencia extrema: no tengo más tiempo, dice la paciencia" 40 . La paciencia urgente, que no puede aguardar plazo alguno, señala tanto al principio de justicia como al de responsabilidad: "el extremo de la paciencia estando en relación con el extremo de la responsabilidad" 41 . Fuera de la posibilidad de tomarse su tiempo, de consultar un programa, la justicia reclama lo inmediato: "La justicia (la justicia para con los demás [autrui]) se distingue porque no soporta aplazamientos" 42 .

En este mismo sentido, Derrida, bajo el título "la urgencia que obstruye el saber", muestra esta relación entre la urgencia y la justicia, una compleja relación que conduce a una aparente paradoja en esta reflexión temporal entre el tiempo del desastre y el tiempo del apocalipsis:

Ahora bien, la justicia, por muy no-presentable que sea, no espera. Para ser directo, simple y breve, diré lo siguiente: una decisión justa es necesaria siempre inmediatamente, enseguida, lo más rápido posible. La decisión no puede procurarse una información infi-

\footnotetext{
39 Blanchot 1980, op. cit. (nota 1), p. 122.

40 Ibidem, p. 34.

41 Ibidem, p. 118

42 Blanchot 2003, op. cit., (nota 31), p. 97.
} 
nita y un saber sin límite acerca de las condiciones, las reglas o los imperativos hipotéticos que podrían justificarla. [...] tal decisión es a la vez sobreactiva y padecida, encierra algo de pasivo, por no decir de inconsciente, como si el que decide fuera libre sólo si se dejara afectar por su propia decisión y como si ésta le viniera de otro. ${ }^{43}$

Varios motivos de esta definición de justicia muestran una gran proximidad entre Derrida y Blanchot. Por una parte, cabe destacar la urgencia de la justicia, pero, sobre todo, el aspecto más complejo es el de un imperativo atravesado por la noción de pasividad ligada a su vez a la de libertad. Si es cierto que Derrida parece hacer referencia a una pasividad en el sentido corriente del término, ligándola incluso a lo inconsciente del que Blanchot la había separado, vemos también cómo se radicaliza cuando afirma que es una decisión que llega desde fuera, como si la decisión siempre estuviese afectada por el otro. Por eso mismo, no se trata de la decisión responsable sino de la decisión que hace responsable. En Politicas de la amistad se puede leer: "Una teoría del sujeto es incapaz de dar cuenta de la mínima decisión [...] La decisión pasiva, condición del acontecimiento, es siempre en mí, estructuralmente, otra decisión, una decisión desgarradora como decisión del otro" 44 .

La libertad ya no se presenta como la capacidad de decisión consciente y voluntaria en la que se sustenta el conocimiento aparentemente necesario para el ejercicio de la justicia. La libertad sólo es tal si está afectada por lo que no forma parte de la decisión consciente y voluntaria sin tampoco hundirla en su contrario. Derrida deja intervenir al otro, un "como si ésta viniera del otro" para mostrar la paradoja que Blanchot expondrá en La comunidad inconfesable en los siguientes términos: "«Yo» no soy libre para con el prójimo (autrui) si siempre soy libre de declinar la exigencia que me deporta de mí mismo y en último término me excluye de mí" 45. Este mismo exceso, donde la libertad se sitúa a la altura de la pasividad definida por Blanchot, corresponde al desajuste que Derrida señala como la imposibilidad para procurarse todo el saber necesario, de forma que si aún se trata de una decisión propia, al mismo tiempo esta responsabilidad conlleva un cambio de lo que supone el estatuto del "yo" como sujeto agente pero también como simple sujeto pasivo, como mero receptor de una responsabilidad. Esta urgencia pone así frente a lo desconocido y no ante lo ya fundado. Blanchot lo expresa de la siguiente manera refiriéndose a la responsabilidad:

43 Derrida, J., Fueza de ley. El "fundamento místico de la autoridad", trad. de Adolfo Barberá y Patricio Peñalver, Madrid, Tecnos, 2008, pp. 60-61.

44 Derrida, J., Políticas de la amistad, trad. de Patricio Peñalver y Francisco Vidarte, Madrid, Trotta, 1998, pp. 86-87.

45 Blanchot, M., La comunidad inconfesable, trad. de Isidro Herrera, Madrid, Arena Libros, 1999, p. 76. 
[...] de la responsabilidad no puedo hablar si no es separándola de todas las formas de la conciencia-presente (voluntad, resolución, interés, luz, acción reflexiva, pero también, quizá, de lo no-voluntario, lo no consentido, lo gratuito, lo inactivo, lo oscuro que se alza de la consciencia-inconsciencia), si se enraíza ahí donde no hay fundamento, donde ninguna raíz se puede fijar, si entonces ella impide todo cimiento y nada individual puede encargarse de ello. 46

Esta urgencia de la justicia implica la ruptura con la teleología apocalíptica pero sin descartar un cierto apocalipsis, pudiéndose afirmar un apocalipsis sin apokalupsis, es decir, sin revelación ni descubrimiento. En La comunidad inconfesable, Blanchot señala que "la urgencia de socorrer al prójimo altera cualquier estudio y se impone como aplicación de la Ley que siempre precede a la Ley"47. De esta forma se puede ver que la justicia como respuesta a la responsabilidad no puede proceder de ninguna legislación anterior que la regule. Ha de ser siempre la excepción, la excepcionalidad, por ello también lo extraordinario, es decir, aquello que "no se enuncia en ningún lenguaje ya formulado"48. De esta forma entendemos que, en la medida en que cada juicio es extraordinario, "no porque esté reservado para el fin de los tiempos; al contrario, la justicia no espera, está a cada instante por cumplir, por dictar, por meditar también (por aprender)" 49 , dice, cada vez, el fin del mundo. Pues si seguimos esta última cita de Blanchot, la urgencia de cada situación singular, de cada acto que se desea justo, ha de romper con todo futuro y con todo dato anterior: "Cada acto justo (¿lo hay?) hace del día el último día o -como dice Kafka- el ultimísimo al no situarse en la continuidad ordinaria de los días sino de lo ordinario más ordinario haciendo lo extraordinario" 50.

Que la justicia sea urgente y que se quiera ya, ahora, no entra por lo tanto en contradicción con este tiempo del no-advenimiento que se abre en la diferencia entre la venida (recordemos la llamada: "Ven") y lo que no llega. La justicia que pide lo inmediato, que no puede esperar, que no retrasa la decisión a un futuro, implica este "Ven" interminable.

En la temporalidad del desastre se combinan los tiempos aparentemente contradictorios del ahora, de lo urgente e inminente y el de un imposible presente; el de un pasado inmemorial y el de un porvenir que rompe con un futuro calculable. El ruego o la exigencia que el "ven" emblematiza no es la llamada que pide la manifestación, el advenimiento del sentido o de la verdad, su descubrimiento final. No es la llamada a la confluencia donde el tiempo se liga a la presencia y la presencia

\footnotetext{
46 Blanchot 1980, op. cit. (nota 1), p. 29.

47 Blanchot 1999, op. cit. (nota 43), p. 75.

48 Ibidem.

49 Blanchot 1980, op. cit. (nota 1), p. 122.

50 Ibidem.
} 
al presente. Este "ven" es un abandono como abandono ante lo que llega, un abandono como principio de la pasividad y de la paciencia que no puede proceder de un sujeto que voluntariamente se abandona. Es la pasividad la que abre a una espera sin horizonte, a una espera que espera más allá de lo esperado, una espera a la que ninguna presencia ni afirmación podría poner fin. Una espera, por lo tanto, que no espera la resolución del momento de la indecisión, sino que es la indecisión misma del paso, la decisión que se sostiene en el movimiento del paso. 